\title{
Analysis of behavioral changes in dairy cows associated with claw horn lesions
}

\author{
K. Nechanitzky, ${ }^{*}$ A. Starke,† B. Vidondo,‡ H. Müller,† M. Reckardt,† K. Friedli,§ and A. Steiner ${ }^{\star 1}$ \\ ${ }^{*}$ Clinical for Ruminants, Vetsuisse-Faculty, University of Bern, 3012 Bern, Switzerland \\ †Clinic for Ruminants and Swine, Faculty of Veterinary Medicine, University Leipzig, An den Tierkliniken 11, D - 04103 Leipzig, Germany \\ ¥Veterinary Public Health Institute, Vetsuisse-Faculty, University of Bern, 3012 Bern, Switzerland \\ §Federal Food Safety and Veterinary Office, Centre for Proper Housing of Ruminants and Pigs, 8356 Ettenhausen, Switzerland
}

\begin{abstract}
Detecting lame cows is important in improving animal welfare. Automated tools are potentially useful to enable identification and monitoring of lame cows. The goals of this study were to evaluate the suitability of various physiological and behavioral parameters to automatically detect lameness in dairy cows housed in a cubicle barn. Lame cows suffering from a claw horn lesion (sole ulcer or white line disease) of one claw of the same hind limb $(\mathrm{n}=32$; group $\mathrm{L})$ and 10 nonlame healthy cows (group C) were included in this study. Lying and standing behavior at night by tridimensional accelerometers, weight distribution between hind limbs by the 4-scale weighing platform, feeding behavior at night by the nose band sensor, and heart activity by the Polar device (Polar Electro Oy, Kempele, Finland) were assessed. Either the entire data set or parts of the data collected over a 48-h period were used for statistical analysis, depending upon the parameter in question. The standing time at night over $12 \mathrm{~h}$ and the limb weight ratio (LWR) were significantly higher in group $\mathrm{C}$ as compared with group L, whereas the lying time at night over $12 \mathrm{~h}$, the mean limb difference $(\Delta$ weight $)$, and the standard deviation (SD) of the weight applied on the limb taking less weight were significantly lower in group $\mathrm{C}$ as compared with group L. No significant difference was noted between the groups for the parameters of heart activity and feeding behavior at night. The locomotion score of cows in group L was positively correlated with the lying time and $\Delta$ weight, whereas it was negatively correlated with LWR and SD. The highest sensitivity (0.97) for lameness detection was found for the parameter SD [specificity of 0.80 and an area under the curve (AUC) of 0.84]. The highest specificity
\end{abstract}

Received July 13, 2015.

Accepted December 28, 2015

${ }^{1}$ Corresponding author: adrian.steiner@vetsuisse.unibe.ch
(0.90) for lameness detection was present for $\Delta$ weight (sensitivity $=0.78$; AUC $=0.88$ ) and LWR (sensitivity $=0.81 ; \mathrm{AUC}=0.87)$. The model considering the data of SD together with lying time at night was the best predictor of cows being lame, accounting for $40 \%$ of the variation in the likelihood of a cow being lame $($ sensitivity $=0.94 ;$ specificity $=0.80 ; \mathrm{AUC}=0.86) . \mathrm{In}$ conclusion, the data derived from the 4-scale-weighing platform, either alone or combined with the lying time at night over $12 \mathrm{~h}$, represent the most valuable parameters for automated identification of lame cows suffering from a claw horn lesion of one individual hind limb. Key words: dairy cow, lameness, weighing platform, claw horn lesion

\section{INTRODUCTION}

Orthopedic disorders causing lameness belong to the most common and economically most relevant production diseases of dairy cattle worldwide (Bennett et al., 1999). The prevalence of lameness of dairy cattle in European countries and the United States ranges between 5 and 48\% (Manske et al., 2002; Espejo et al., 2006; Amory et al., 2008; Bicalho et al., 2009; Dippel et al., 2009a,b, Barker et al., 2010; Becker et al., 2014b). Reduced milk yield and fertility, increased risk of culling, treatment costs, and additional expenditure for extra labor cause considerable economic loss (Kossaibati and Esslemont, 1997; Warnick et al., 2001; Green et al., 2002; Garbarino et al., 2004; Amory et al., 2008; Bruijnis et al., 2010).

Many farmers were unaware of the financial consequences caused by lame animals and did not realize how the lameness problem affected the productivity and profitability of their dairy enterprises (Leach et al., 2010a,b). In an investigation of 222 English dairy farms, $90 \%$ of the farmers did not judge lameness as being a big issue, although the average prevalence of lameness was 36\% (Leach et al., 2010a). However, farmers' interest in good claw health is a decisive factor 
for low within-herd lameness prevalence (Becker et al., 2014a).

Lesions causing lameness were located in the area of the feet in $88.3 \%$ of the cases, $84 \%$ of the foot lesions occurred in the hind feet, and $85 \%$ of these lesions affected the outer claw (Russell et al., 1982). Digital dermatitis, heel horn erosion, sole ulcers, and white line disease were shown to be the predominant claw lesions of dairy cows (Manske et al., 2002; Barker et al., 2010; Becker et al., 2014a,b).

Cows are a prey species and rather stoic: they seldom show signs of pain until the stimulus is severe (Anil et al., 2005; Hudson et al., 2008). However, it has been shown that slight behavioral changes are present in lame cows. Cows suffering from pain associated with lameness changed their behavior to reduce discomfort (Hudson et al., 2008). These behavioral changes encompass, for example, decreased movement or locomotion, decreased feed intake, reduced mental responsiveness, decreased interaction with other animals, tooth grinding, and changes in posture and gait. In practice, lame cows are often insufficiently identified and treated (Bruijnis et al., 2010). The mean time from the onset of lameness to clinical recognition by the farm personnel was $27 \mathrm{~d}$ (Tranter and Morris, 1991).

In general, veterinary treatments and management decisions are more effective the earlier they are taken once the disease is established (González et al., 2008). A decrease in milk yield lasted from 4 mo before individual cows were diagnosed clinically lame until 5 mo after this point in time (Green et al., 2002). Interest is increasing in automated methods to detect lameness, as early detection is difficult and the economic effect is significant (Espejo et al., 2006; Chapinal et al., 2010). Therefore, various automated tools were developed and tested with the aim to improving the assessment and early detection of lameness on dairy farms. Using the 4-scale weighing platform, it was found that lame cows reduced the weight-bearing of the affected limb (Rushen et al., 2007; Pastell et al., 2010). Furthermore, lame cows, as compared with nonlame cows, showed a higher asymmetry of weight within each pair of limbs and had a greater standard deviation of the weight applied on each limb over time (Neveux et al., 2006; Rushen et al., 2007; Chapinal et al., 2010). The latter parameter proved to be the most accurate predictor of whether a cow was lame or not. The use of tridimensional accelerometers revealed that grazing lame dairy cows, as compared with nonlame cows, spent more time lying and had fewer lying bouts per day (SepúlvedaVaras et al., 2014). Generally, lying bouts of lame cows lasted longer than those of nonlame cows (Chapinal et al., 2010; Yunta et al., 2012; Sepúlveda-Varas et al., 2014). Acute locomotion disorders lead to a decrease in
(1) feed intake, (2) number of meals, (3) visits to the feeders, and (4) a considerable decrease in eating time (González et al., 2008). By using the noseband pressure sensor technology, it is currently possible to detect, differentiate, and record eating and rumination behavior automatically (Braun et al., 2014). The analysis of heart rate variability (HRV) as a parameter of heart activity represents another suitable automated method to assess stress and welfare status in farm animals (von Borell et al., 2007). Heart rate variability reflects the balance between the sympathetic and parasympathetic tone and delivers information on the stress response of the autonomic nervous system (Mohr et al., 2002; von Borell et al., 2007). In general, sympathetic activity tends to increase heart rate (HR) and decrease HRV, whereas parasympathetic activity tends to decrease HR and increase HRV. Lower values in HRV and higher values in HR were found to be associated with higher levels of stress in goats (Nordmann et al., 2011), and this can also be expected in cows.

It was the aim of the current study to evaluate the suitability of various automated methods (measures of weight distribution, lying and standing behavior at night, feeding behavior at night, and heart activity) to assess altered behavior in cows associated with lameness caused by a claw horn lesion of one individual hind claw.

\section{MATERIALS AND METHODS}

\section{Cows and Housing}

The study was carried out between April 2013 and March 2014 on a commercial dairy farm with around 900 lactating German Holstein cows located close to Chemnitz, Germany. Cows were housed in a group of 30 to 40 moderately lame cows (not used for this study) in a freestall pen with concrete slatted floor and rubber floor cubicles. Multiparous German Holstein dairy cows $[\mathrm{n}=44$; parity $=3.09 \pm 1.22($ mean $\pm \mathrm{SD})$; DIM $=104.95 \pm 47.03 ; \mathrm{BW}=625.63 \pm 69.91 \mathrm{~kg} ;$ daily milk yield at $\mathrm{d} 1=34.40 \pm 7.18 \mathrm{~kg}]$ were included in the study. Cows were milked twice daily, in a carrousel milking parlor, at approximately 1400 and $0200 \mathrm{~h}$ and fed a TMR diet once daily that was formulated to meet the requirements for lactating dairy cows. Water was available ad libitum from self-filling troughs. Preventive foot trimming was routinely performed 3 times per year by a certified foot trimmer and therapeutic foot trimming whenever the farm personnel identified a cow as being lame. The experimental protocol was approved by the Animal Care Committee of the University of Leipzig (Landesdirektion Sachsen, Referat 24 - Veterinärwesen und Lebensmittelüberwachung, Pharmazie, 
GMP Inspektorat, Anzeigennummer: A 30/12, Registriernummer: 24-9168.21/4/30).

\section{Selection of Cows}

Once every 4 wk, 4 cows [1 nonlame cow (control $=$ group $\mathrm{C}$ ) and 3 lame cows (lame $=$ group L)] were selected and moved to the lame cow pen. Criteria for inclusion in group $\mathrm{C}$ were that cows were in second lactation, clinically healthy and not lame [(locomotion score $\leq 1$, according to Offinger et al. (2013)]. The criteria for inclusion in group $\mathrm{L}$ were that cows were in second or later lactation, clinically healthy except for the presence of lameness [locomotion score $>1$, according to Offinger et al. (2013)] and had a claw horn lesion of one hind claw. The most relevant representatives of these claw horn lesions include sole ulcers and white line disease (Cramer et al., 2008; Egger-Danner et al., 2015). The criteria for immediate exclusion of cows during the selection process were (1) presence of signs of systemic disease or (2) painful orthopedic lesions other than the claw lesion of interest, (3) treatment with nonsteroidal anti-inflammatory drug or steroidal anti-inflammatory drug within $28 \mathrm{~d}$ before the experiment, (4) not within the withdrawal period following antibiotic treatment, (5) pregnancy $>7 \mathrm{mo}$, or $(6)>240$ DIM at the time of selection. One cow from group L was excluded from the study because it did not adequately become accustomed to the experimental procedure, and one cow from group $\mathrm{C}$ was excluded at the end of data acquisition during data validation (viewing of blinded videos and photographs) because it was lame [score 4/13, according to Offinger et al. (2013)]. In total, 42 cows (10 from group $\mathrm{C}$ and 32 from group L) were included in the final statistical analysis.

\section{Experimental Procedure}

On d 1, cows were selected and moved to the lameness pen according to the result of a general clinical and a thorough orthopedic examination, including locomotion scoring and visual inspection of the claws, was completed with the cows being restrained in a trimming chute. At d 2, clinical and orthopedic examinations were repeated, and cows were equipped with the electronic health monitoring instruments, which remained in place for continuous recording until the end of the study (d 6); these included (1) 2 tridirectional accelerometers (RumiWatch, Itin+Hoch, Liestal, Switzerland) attached to the right and left metatarsal regions, (2) 1 noseband pressure sensor (RumiWatch, Itin+Hoch) attached to the head of the cow, and (3) a heart activity sensor (Polar Team 2 pro, Polar Electro Oy, Kempele, Finland) attached to the thorax with a belt. From d 3 to 6 , cows were locomotion scored and restrained in the chute of the weighing platform for measuring weight distribution among limbs twice daily. All clinical examinations were performed by the study veterinarians, whereas functional claw trimming was performed by an experienced professional claw trimmer.

\section{Data Collection}

General Clinical Examination. At daily clinical examination, the following health parameters were recorded: posture, general behavior, rectal body temperature, HR, respiratory rate, rumen fill, rumen motility, swing and percussion auscultation, abdominal shape, and appearance and amount of feces. At initial examination (d 1), the glutaraldehyde test for semiquantitative analysis of blood fibrinogen and $\gamma$-globulin concentration (Doll et al., 1985), BCS according to Edmondson et al. (1989), measuring of BW with the 4-scale weighing platform, and measuring the withers height using a cattle-measuring stick (Hauptner u. Herberholz GmbH \& Co. KG, Solingen, Germany) were additionally performed.

Examination of the Claws and Locomotion Score. All claws were examined in the trimming chute and the claw lesions photographed and classified by 2 of 3 previously trained study veterinarians (H. Müller, K. Nechanitzky, or M. Reckardt) according to Starke et al. (2007). Locomotion was scored daily at a fixed time between 0800 and $1000 \mathrm{~h}$, at rising, standing, and while walking down a $15-\mathrm{m}$ long by $1.5-\mathrm{m}$ wide concrete slatted passageway 2 times, so that the locomotion could be assessed from the side and from behind. To ensure that the cows walked in a consistent manner, a handler walked behind the cows encouraging them to walk when necessary. Two of the 3 study veterinarians immediately assigned a collective locomotion score to each cow for each day using a numerical rating system with a range from 0 to 13 (Table 1 ), where $0=$ nonlame and 13 = severely lame (Offinger et al., 2013), adapted according to Dirksen (1990). Each cow was additionally videotaped (Handycam HDR-XR 155, Sony, Tokyo, Japan) once from the right side and once from behind for final scoring during data validation at the end of the study. Cows were acclimated with the procedure during d 2 to 4 , and the arithmetic mean of data from d 5 and 6 of each cow were used for further analysis.

Lying and Standing Behavior at Night. One tridimensional accelerometer (RumiWatch, Itin+Hoch; length $=210 \mathrm{~mm}$, width $=55 \mathrm{~mm}$, depth $=29 \mathrm{~mm}$, weight $=130 \mathrm{~g}$ ) was attached with a strap to the metatarsus above the fetlock of both hind limbs. Acceleration was recorded at $10 \mathrm{~Hz}$ and raw data stored on the secure digital memory card with a capacity of 
Table 1. Locomotion score according to Offinger et al. (2013) with 5 major lameness scores (I to V; modified according to Dirksen, 1990; Flower and Weary, 2006) and 13 locomotion scores for the affected hind limb used in the present study

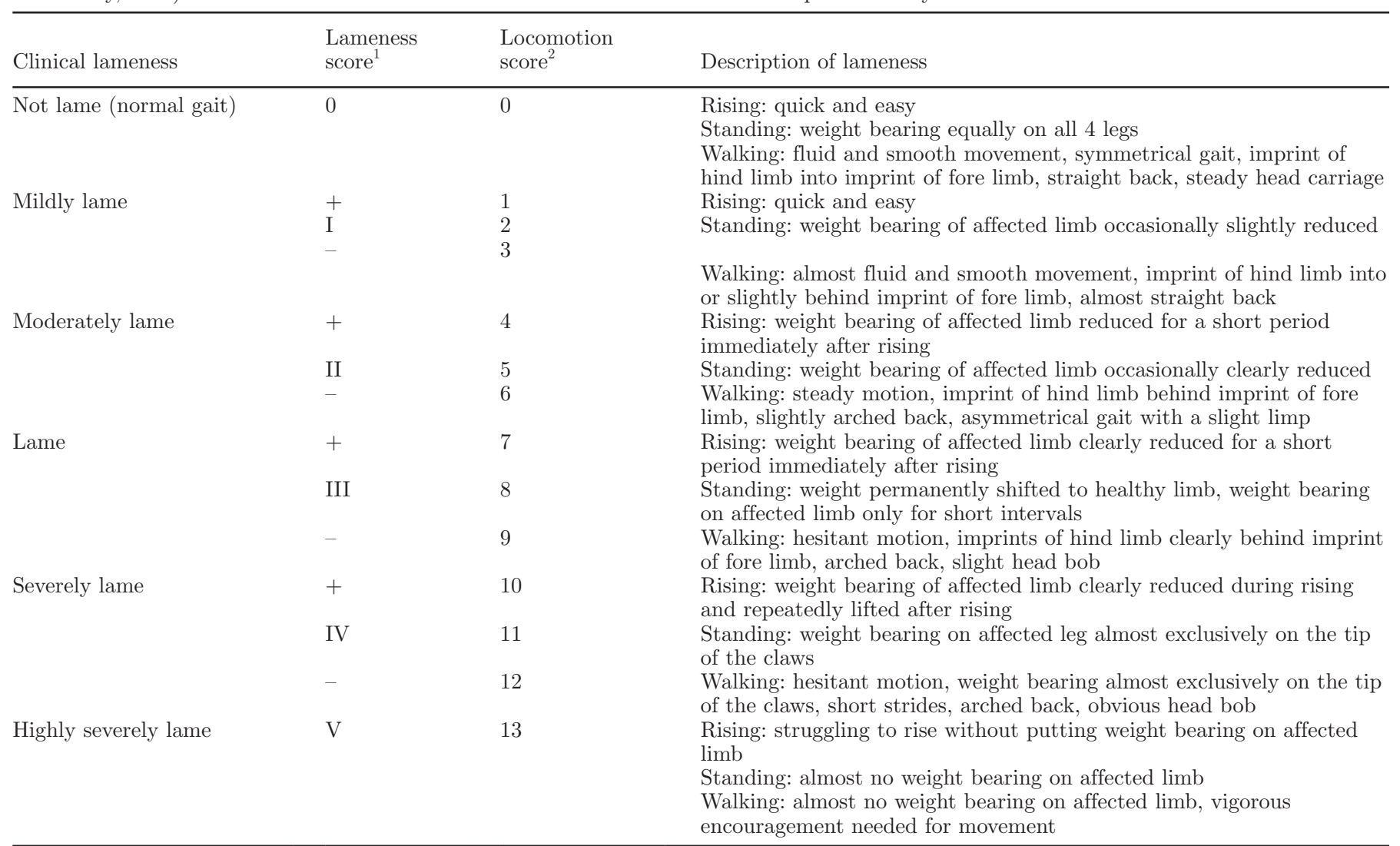

${ }^{1}$ Concerning lameness score, a + signifies the tendency of the main score toward the lower score and a - toward the higher score.

${ }^{2}$ The locomotion score was assessed during rising, standing, and walking down two times a 15-m long by 1.5-m wide concrete slatted passageway.

$512 \mathrm{MB}$ integrated in the data logger case. Cows were familiarized with the loggers during d 2 and 3 , and the arithmetic mean of two 12 -h periods at night (1700 to $0500 \mathrm{~h}$ ) of $\mathrm{d} 4$ and 5 of each parameter and cow was used for statistical analysis. The RumiWatch Converter V0.7.2.17 (Itin+Hoch) was used to calculate the following parameters of the lying and standing behavior at night from the raw data files (arithmetic mean of both data loggers): duration of lying and standing time and number of rising and lying down events.

Weight Distribution Between Hind Limbs. To measure weight distribution between hind limbs while the cow is standing, the method described by Neveux et al. (2006) and Chapinal et al. (2009a) was used. For this purpose, cows were restrained in a manual steel chute with movable side panels, mounted on a weighing platform (Itin + Hoch). The platform contained 4 independent recording units $(78 \times 55 \mathrm{~cm})$ with one hermetically sealed load cell (HBM, Hottinger Baldwin Messtechnik AG, Volketswil, Switzerland) each and covered with individual rubber mats $(10 \mathrm{~mm}$ thickness). The registered weights were not affected by the position of the claws on the respective recording unit. Recording was manually started when the cow was in the right position, standing calm with every limb on the appropriate unit. If the measured total weight deviated by more than $5 \%$ from the originally measured total BW of the cow, data collection was stopped automatically and was continued when the cow was in the adequate position again, which was achieved by gently manipulating the cow. This way, data were excluded when a forced closure was present. The total recording period per session lasted 5 min. Data from each of the 4 scales were recorded at a sampling rate of 10 readings/s. The cows had been familiarized with the weighing platform and the procedure by standing at least 3 times on the platform before the data collection started, and the arithmetic mean per cow was calculated from the second weighing of $\mathrm{d} 4$, both weighings of $\mathrm{d} 5$, and the weighing of $\mathrm{d} 6$. The hind limb taking less weight was defined as the hind limb with the lower mean weight taken over the 4 data collection periods. Parameters, calculated for the hind limbs and each 5 min interval, were the mean weight applied on 
each limb, the standard deviation (SD) of the weight applied on the limb taking less weight as a measure of weight shifting between hind limbs (Rushen et al., 2007 ), the mean limb difference ( $\Delta$ weight) calculated by subtracting the mean weight of the hind limb taken less weight from that taking more weight, and the limb weight ratio (LWR) between the hind limb taking less weight and that taking more weight as indicators of asymmetry in weight distribution between the hind limbs (Pastell and Kujala, 2007).

Feeding Behavior at Night. To continuously measure feeding behavior at night, the RumiWatch (Itin+Hoch) nose band sensor was used, consisting of an oil-filled tube positioned over the dorsal side of the nose, a pressure sensor, and a wireless transmitter which registered jaw movements with a frequency of 10 readings per second. Data were exported to a personal computer, and the algorithm 0.9.6 of RumiWatch (Itin+Hoch) was used for calculation of the following feeding parameters: ruminate time (time, cows spent ruminating), eat time (time, cows spent eating), ruminate chew (number of rumination chews), eat chew (number of eating chews), bolus (number of rejected boli), and chews per bolus (number of chews per bolus). The cows were familiarized with the nose band sensors on d 2 and 3, and the arithmetic mean of each parameter collected during two 12 -h periods at night (1700 to $0500 \mathrm{~h}$ ) of d 4 and 5 of each cow was used for statistical analysis.

Heart Activity Including $\boldsymbol{H R V}$. To continuously measure heart activity, individual cows were fitted with the POLAR (Polar Team 2 pro, Polar Electro Oy) recording device, consisting of 2 electrodes and one recorder or transmitter attached to a thorax belt. Data were collected at a sampling rate of $200 \mathrm{~Hz}$. The recorders or transmitters were replaced daily, because the battery capacity was sufficient for $36 \mathrm{~h}$ only. The 24-h data of each cow was daily transferred via infrared transmission to a personal computer. The cows were familiarized with the thorax belts during d 3 and 4 . Two 5-min periods per animal per day were analyzed, when the cow was lying for at least 5 min and when it was standing immediately after a lying period. $\mathrm{Ku}-$ bios HRV software (Department of Applied Physics, University of Kuopio, Joensuu, Finland) was used to analyze the data. To remove trend components, data were detrended and artifact corrections were made following established procedures described by (Tarvainen et al., 2014). The HRV is usually nonstationary and slow linear or more complex trends in the HRV signal can cause distortion of HRV analysis. The Kubios HRV program uses a detrending procedure based on smoothness priors approach (Tarvainen et al., 2002). The smoothness parameter was set at $500 \mathrm{~ms}$. The follow- ing parameters of heart activity were calculated: mean HR, beat-to-beat interval (RR), standard deviation of RR interval (SDRR), root mean square of successive RR differences (RMSSD), and the geometric means standards deviation 1 (SD1) and 2 (SD2). For calculation of SD1 and SD2, the duration of each RR interval was plotted against the duration of the proceeding $\mathrm{RR}$ interval (Poincaré plot). The software fitted an ellipse on the plot to parameterize the shape of the plot. The ellipse was according to the line-of-identity $(R R j=R R j$ $+1)$ at $45^{\circ}$ to the $\mathrm{x}$-axis. The parameter SD1 can be considered as measuring short-term variability, mainly caused by parasympathetic activity, whereas SD2 measures long-term variability (von Borell et al., 2007; Tarvainen et al., 2014). The arithmetic mean of each parameter per cow of d 5 and 6 was used for statistical analysis.

\section{Statistical Analysis}

Statistical analysis was performed with NCSS statistic package (ver. 9, NCSS LLC, Kaysville, UT) using the arithmetic mean per cow of the 10 nonlame and 32 lame animals. Descriptive statistics showed that all variables were normally distributed. To elucidate differences between the 2 types of claw horn lesions (sole ulcer versus white line disease) they were compared, using ANOVA for each variable separately. As significant differences were not evident, both types of claw horn lesions were combined to group L for further analyses. To compare group $\mathrm{C}$ with all cows with claw horn lesions (group L), ANOVA was carried out taking each numeric parameter as the outcome and the classification lame or nonlame as the independent or grouping variable. Only the parameters that showed differences in the ANOVA were then used as independent parameters for further analysis, taking the classification lame or nonlame as the binary outcome. The significance level was set at $\alpha=0.05$. To evaluate how well each independent parameter or combinations of parameters could be used for an automated detection of lame cows with a claw horn lesion, we performed logistic regression models and a receiver operating characteristic (ROC) analysis. The ROC analysis renders specificity, sensitivity, and area under the curve (AUC) for each model (Hanley and McNeil, 1982; Lasko et al., 2005); the higher these values, the better the model. Combinations of parameters which were highly or moderately correlated $(\mathrm{r}>0.2)$ or which were derived from the same automated lameness detection tool, were avoided in the models, as by definition model covariates need to be independent. Correlations were checked using Pearson correlation coefficients. 
Table 2. Mean, SD, median, lower 95\% confidence level (LCL), and upper 95\% confidence level (UCL) of several variables describing the cows, the lying and standing behavior at night, and the weight distribution between hind limbs of control $(\mathrm{n}=10)$ and lame $(\mathrm{n}=32)$ cows ${ }^{1}$

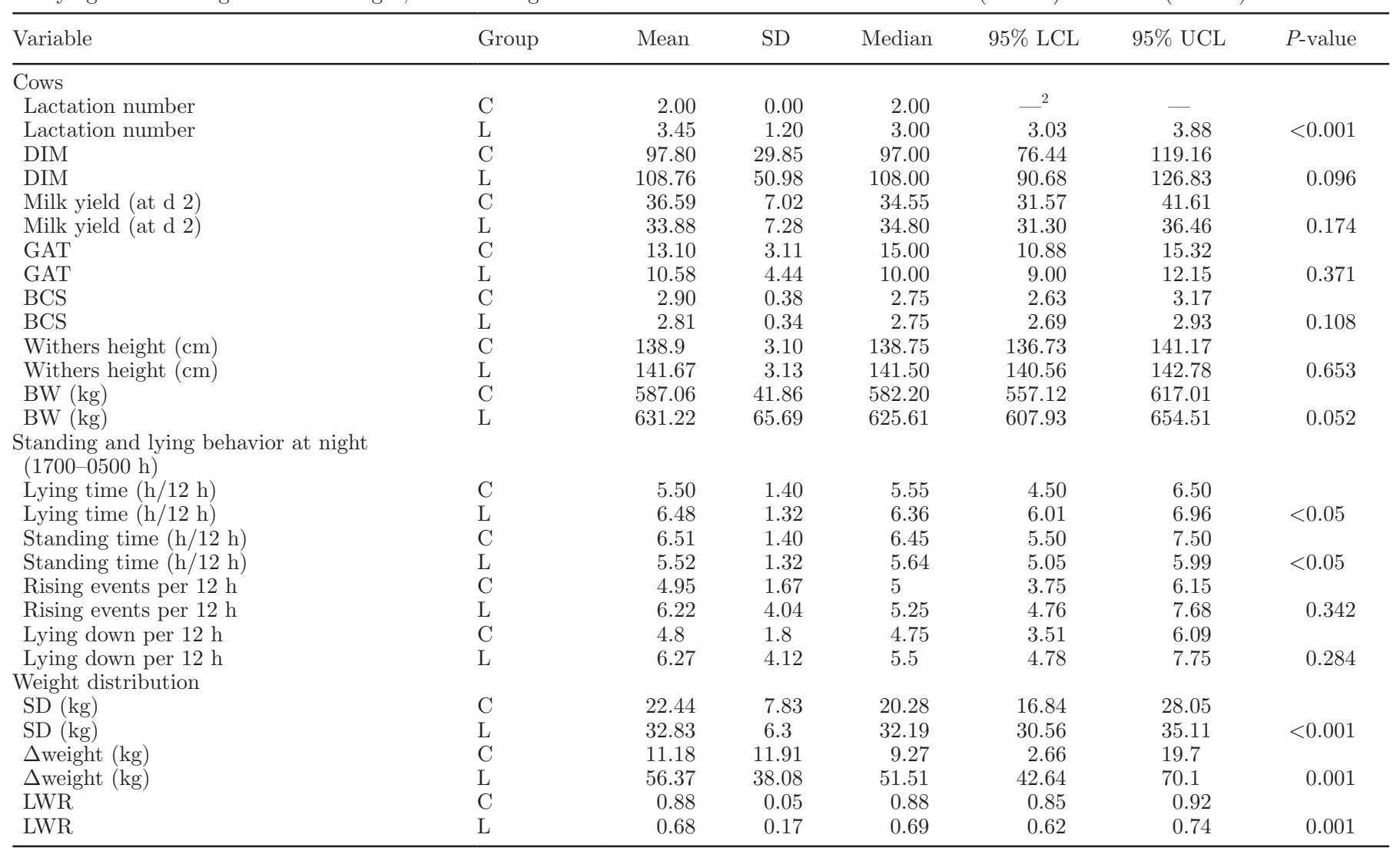

${ }^{1}$ Group $\mathrm{C}=$ group control; group $\mathrm{L}=$ group lame; GAT $=$ glutaraldehyde test in min; Lying time: time cows spent lying; standing time $=$ time cows spent standing or walking; $\mathrm{SD}=$ standard deviation of the weight applied to the limb taking less weight; $\Delta$ weight $=$ weight difference between the hind limb taking more and that taking less weight; LWR = limb weight ratio.

${ }^{2}$ Not applicable as lactation number 2 was a selection criterion for cows of group C.

\section{RESULTS}

\section{Cows}

The lactation number of cows of group L (mean $\pm \mathrm{SD}=3.45 \pm 1.20)$ was significantly $(P<0.001)$ higher as compared with group $\mathrm{C}$ (mean $=2$; selection criteria). Cows of groups $\mathrm{C}$ and $\mathrm{L}$, however, were not significantly different concerning DIM, milk yield, glutaraldehyde test, BCS, withers height, and BW. Data are given in Table 2 .

\section{Locomotion Scores and Claw Lesions}

Cows of group L had a locomotion score of $5.17 \pm$ 1.54, ranging from 2 to 9 , whereas all cows of group $\mathrm{C}$ had a locomotion score of 0 or 1 (selection criteria; $P<$ 0.001). None of the cows of group $\mathrm{C}$ showed any claw lesion. In group L, a sole ulcer was present in 15 cows, and white line disease in 17 cows.

\section{Lying and Standing Behavior at Night}

Lame cows spent significantly more $(P=0.049)$ time lying $(6.48 \pm 1.32 \mathrm{~h} / 12 \mathrm{~h})$ and less time $(P=0.049)$ standing and walking $(5.52 \pm 1.32 \mathrm{~h} / 12 \mathrm{~h})$, respectively, than nonlame cows $(5.50 \pm 1.40$ and $6.51 \pm 1.40$ $\mathrm{h} / 12 \mathrm{~h}$; Table 2). The number of rising and lying down events was not significantly different between groups $(P$ $=0.342$ and $P=0.284$ for lame and nonlame, respectively). The results of the ROC analyses and the goodness of fit of logistic regression models of the significant parameters standing time and lying time at night are given in Table 3.

\section{Weight Distribution}

The 3 parameters of weight distribution between hind limbs generated from the weighing platform revealed significant differences between groups (Table 


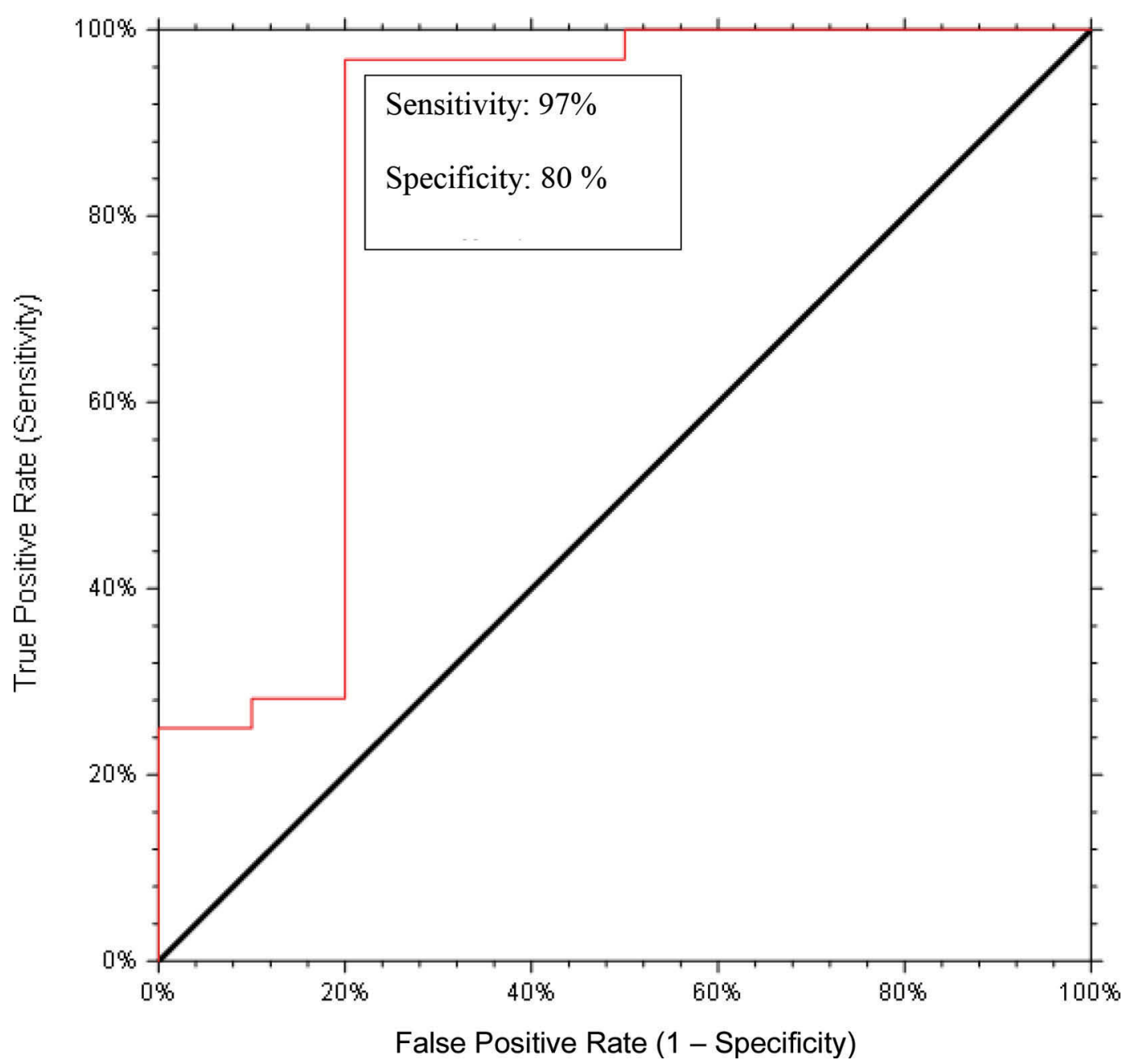

Figure 1. Receiver operating characteristics curve of the parameter standard deviation of the weight distribution of the limb taking less weight of 32 lame and 10 nonlame cows. Color version available online.

$2)$. The $\mathrm{SD}(P<0.001)$ and $\Delta$ weight $(P=0.001)$ were significantly higher in group L as compared with group C, whereas the LWR was significantly lower $(P$ $=0.001)$ in group $\mathrm{L}$ as compared with group $\mathrm{C}$. The ROC analyses revealed the highest sensitivity (0.97) for the parameter SD, with a specificity of 0.80 and an AUC of 0.84 (Figure 1) at a cut-off value of $22.82 \mathrm{~kg}$, and the highest specificity (0.90) for the parameters $\Delta$ weight (sensitivity $=0.78 ; \mathrm{AUC}=0.88$ ) and LWR $($ sensitivity $=0.81 ; \mathrm{AUC}=0.87$; Table 3$)$.

Table 3. Results of the receiver operating characteristics and the goodness of fit of logistic regression models of different variables, describing the weight distribution between hind limbs, the lying and standing behavior at night $(1700-0500 \mathrm{~h})$ and combinations of independent or minimally correlated, automatically assessed variables of control $(\mathrm{n}=10)$ and lame $(\mathrm{n}=32)$ cows $^{1}$

\begin{tabular}{lccccc}
\hline Variable & Sensitivity & Specificity & Cut-off value & AUC & $\mathrm{R}^{2}$ \\
\hline SD $(\mathrm{kg})$ & 0.97 & 0.80 & 22.82 & 0.84 & 0.34 \\
$\Delta$ weight $(\mathrm{kg})$ & 0.78 & 0.90 & 25.32 & 0.88 & 0.34 \\
LWR & 0.81 & 0.90 & 0.84 & 0.87 & 0.34 \\
Standing time $(\mathrm{h} / 12 \mathrm{~h})$ & 0.75 & 0.70 & 6.01 & 0.71 & 0.09 \\
Lying time $(\mathrm{h} / 12 \mathrm{~h})$ & 0.78 & 0.60 & 5.64 & 0.71 & 0.09 \\
SD $(\mathrm{kg})$ and lying time $(\mathrm{h} / 12 \mathrm{~h})$ & 0.94 & 0.80 & 22.82 and 6.00 & 0.86 & 0.40 \\
\hline
\end{tabular}

${ }^{1} \mathrm{SD}=$ standard deviation of the weight applied on the limb taking less weight; $\Delta$ weight $=$ weight difference between the hind limb taking more and that taking less weight; LWR = limb weight ratio; AUC = area under curve; $\mathrm{R}^{2}=$ goodness of fit of variable or combination of variables. 


\section{Feeding Behavior at Night and Heart Activity}

A trend was evident $(P=0.068)$ that cows of group $\mathrm{L}$ had shorter feeding time at night than cows of group C. Neither the other parameters of the feeding behavior nor parameters of the heart activity revealed significant differences between the 2 study groups (data not shown).

\section{Correlations Between Parameters}

Correlations between parameters that revealed to be significantly different between groups $\mathrm{L}$ and $\mathrm{C}$ are given in Table 4. Pearson correlation coefficients exceeding 0.7 included standing time versus lying time and LWR versus $\Delta$ weight. The correlations between $\mathrm{SD}$ and the other 2 parameters collected from the weighing platform (LWR and $\Delta$ weight) and between SD and the standing time or lying time, respectively, were rather low $(\mathrm{r}<0.2)$. In cows of group $\mathrm{L}$, lying time $(\mathrm{r}=0.56)$ and $\Delta$ weight $(\mathrm{r}=0.68)$ were both positively correlated with the locomotion score, whereas SD $(r=-0.46)$ and LWR $(\mathrm{r}=-0.67)$ were both negatively correlated with the locomotion score.

\section{Logistic Regression to Predict Lameness}

The model considering the data of SD and lying time was the best predictor of cows being lame, accounting for $40 \%$ of the variation in the likelihood of a cow being lame $\left(\mathrm{R}^{2}=0.40\right)$, with AUC of 0.86 , a sensitivity of 0.94 , and a specificity of 0.80 (Table 3 ).

\section{DISCUSSION}

The results of our study showed that cows with lameness caused by a superficial claw horn lesion affecting one individual hind foot when compared with nonlame cows were detected with high sensitivity $(0.97)$ and specificity $(0.80)$ by the use of the weighing platform evaluating the parameter SD. Whereas the duration of lying time at night, as determined with 3-directional accelerometers attached to the hind limbs, was significantly higher $(P<0.05)$ in cows of group L as compared with group $\mathrm{C}$, feeding behavior at night and parameters of the HRV did not allow differentiating between lame and control cows.

The study was performed during a 1-yr period. Each time 3 lame cows entered the study they were accompanied by 1 control cow to eliminate unequally distributed effects of season (environmental temperature, humidity, light) and feeding on the 2 experimental groups. Comparison of the groups L and C revealed no differences concerning the cows' production data except for the lactation number. The latter was significantly higher in cows of group L, as only multiparous cows were allowed to enter the study, and only cows in their second lactation were selected for group $\mathrm{C}$, but cows in their second and higher lactations were selected for group L. This was done because parameters of metabolism of clinically healthy second-lactation cows were simultaneously collected and evaluated for a concurrent study.

The locomotion scoring system chosen in our study was previously described by (Offinger et al., 2013). It was preferred to more frequently used locomotion scoring systems, such as the one described by Sprecher et al. (1997) or the numerical rating system by Flower and Weary (2006), because it allowed for a much more detailed differentiation among various degrees of lameness (locomotion scoring range of $0-13$ vs. $1-5$ ). This was judged to be relevant because the degree of correlation between the locomotion score of lame cows and automated parameters of lameness that were significantly different between the 2 groups was of major scientific interest.

Claw horn lesions were chosen as the lameness-causing foot pathologies in our study, because they occur in dairy cattle with a high incidence rate (Manske et al., 2002; Somers et al., 2003; Holzhauer et al., 2008; Becker et al., 2014b), frequently affecting only one hind

Table 4. Pearson correlation coefficiants (r) of significant variables, suitable for the automated assessment of altered behavior in lame $(\mathrm{n}=32)$ and nonlame control cows $(\mathrm{n}=10)$ with a claw horn lesion ${ }^{1}$

\begin{tabular}{lccrrr}
\hline Variable & $\begin{array}{c}\text { Lying time } \\
\text { at night }\end{array}$ & $\begin{array}{c}\text { Standing time } \\
\text { at night }\end{array}$ & SD & $\Delta$ weight & LWR \\
\hline Lying time at night & 1 & -1 & 0.112 & 0.499 & -0.419 \\
Standing time at night & -1 & 1 & -0.112 & -0.499 & 0.419 \\
SD & 0.112 & -0.112 & 1 & 0.120 & -0.114 \\
$\Delta$ weight & 0.499 & -0.499 & 0.120 & 1 & -0.978 \\
LWR & -0.419 & 0.419 & -0.114 & -0.978 & 1 \\
\hline
\end{tabular}

${ }^{1}$ Lying time at night: time cows spent lying at night $(1700-0500 \mathrm{~h})$; standing time at night $=$ time cows spent standing or walking at night $(1700-0500 \mathrm{~h}) ; \mathrm{SD}=$ standard deviation of the weight applied to the limb taking less weight; $\Delta$ weight $=$ weight difference between the hind limb taking more and that taking less weight; LWR $=$ limb weight ratio. 
foot, and are often responsible for lameness (Zahid et al., 2014). Interestingly, the behavior of cows with sole ulcer or white line disease was not different from each other, and, therefore, all the lame cows in our study were gathered into one single group (group L). It may be concluded that these 2 claw pathologies cause a similar degree of pain.

It was decided for our study to only evaluate parameters of automated behavior description with the $\mathrm{Ru}-$ miWatch system that had previously been scientifically validated (Zehner, 2012; Just, 2014). This explains why only the accelerometer parameters standing and lying time and number of rising and lying down events were evaluated (Just, 2014). The pedometer algorithm available at the time of data evaluation was neither validated for the number of steps nor designated to differentiate between limb movements when the cow was standing and such associated with walking. Two 12-h intervals at night instead of two 24-h intervals were used for evaluation of RumiWatch data in our study to avoid the evaluation of intervals during which the behavior of experimental cows was disturbed by external manipulations, such as lameness scoring or forcing the cows to entering the weighing platform.

The lying time at night of lame cows was found to be significantly longer compared with the control cows. The duration of the lying bouts made up the difference, as the number of position changes (rising and lying down events) was not significantly different between groups. This finding is in agreement with previous studies showing similar results (Chapinal et al., 2009b, 2010; Sepúlveda-Varas et al., 2014) and in partial agreement with Yunta et al. (2012), who found that lame cows had longer lying bouts than nonlame cows but total daily lying time was not affected by lameness. Furthermore, it was shown that multiparous cows generally have fewer but longer lying bouts than primiparous cows (Vasseur et al., 2012). This may have had some effect on the results of our study, as cows of group L were older than cows of group C. In agreement with the recent literature, it may be concluded that lying time at night and duration of lying bouts, as retrieved from the data of a single pedometer per cow may be valuable additional co-variables for the automated detection of lame cows. The potential of tridimensional accelerometers attached to the limbs of cows for detection of lameness may not, however, be entirely exhausted. Further development seems warranted, as only variables of the RumiWatch pedometers validated at the time of data evaluation (lying versus standing behavior, but not the walking behavior) were used in the current study.
The weighing platform revealed to be the most valuable individual tool for distinguishing lame from nonlame cows in the current study. This is in general agreement with previous findings described by (Chapinal et al., 2010; Pastell et al., 2010). Nevertheless, sensitivity and specificity were higher in the current study, as previously described. This may be explained by the fact that only cows with a very specific pathology restricted to one individual hind foot were included in group L and only completely nonlame cows were in group $\mathrm{C}$ of the current study. In comparable studies, groups L and C were less narrowly defined (Pastell et al., 2010). Evaluation of the correlations between various variables showed unexpected and novel results. First, the variable SD showed only minor correlation with both the variables $\Delta$ weight and LWR. Second, SD of lame cows was negatively correlated with the locomotion score. The latter result may be surprising; however, taking a closer look, it may well be explained because the variable $\mathrm{SD}$ is a measure of leg load variability or weight shifting (Rushen et al., 2007). If only one foot is affected, slight lameness may be accompanied by more variable weight shifting as compared with severe lameness. Lesions causing severe lameness may be so painful that loading weight on this particular foot is avoided to a high degree, and weight bearing is constantly shifted to the contralateral healthy foot. Pastell and Kujala (2007) already revealed that cows in a severe, painful stage of disease constantly lifted the affected limb to relieve pain. The latter is reflected by the positive correlation between the locomotion score of lame cows and $\Delta$ weight, as found in the current study. Furthermore, it was shown that the lameness detection rate may be improved by combining the results of several measurement sessions of the weighing platform, taken from one and the same cow (Pastell and Kujala, 2007). In the current study, we built from this finding, and the results of 4 weighing sessions performed in 12-h intervals were combined to come up with one mean value for each variable. It remains unclear whether a 4-scale weighing platform incorporated into a milking robot would yield similar results as compared with the stand-alone type used in our study. Behavior specifically associated with the milking procedure may potentially adversely affect the results.

González et al. (2008) found a significant decrease in feed intake of cows with acute locomotion disorders, especially during the main feeding time. This finding is supported by a study by Yunta et al. (2012), who found that lame cows stood up 13 min later and lay down 19 min earlier than nonlame cows relative to the time when the ration was delivered. In line with the findings 
of the recent literature, we found a trend $(P=0.068)$ that the cows from group L spent less time feeding at night as compared with group C.

Data gained by means of the Polar system proved not to be useful to differentiate between lame and nonlame cows. Even though it was shown that the analysis of parameters of the HRV are suitable for detecting acute stress in cattle (Buck et al., 2013), this method was not suitable to distinguish between nonlame and lame cows under the conditions of this experimental setting. Although it may be hypothesized that the basic stress level of the cows of this particular pen may have been generally elevated, the daily composition of this pen was highly variable, as every cow newly recovered from lameness was immediately replaced by a lame cow from another pen.

\section{CONCLUSIONS}

We concluded from the results of this experimental field study that the parameters derived from the weighing platform alone or in combination with the parameter lying time at night represent a valuable data set for identifying lame cows suffering from a claw horn lesion of one individual hind limb when compared with nonlame cows. Variables of feeding behavior at night and of HRV are of minor value in this context. It has to be stressed, however, that the comparison of cows suffering from claw horn lesions with cows showing lameness of other origin or involving both hind limbs was not undertaken in this study.

\section{ACKNOWLEDGMENTS}

This study was generously supported by grants from Boehringer Ingelheim, Ingelheim, Germany, the Swiss Federal Food Safety and Veterinary Office, Liebefeld, Switzerland (FSVO; grant 2.10.04), and the Berne University Research Foundation Switzerland, Bern, Switzerland; accelerometers and noseband sensors were generously provided by ITIN $+\mathrm{HOCH}$, Liestal, Switzerland.

\section{REFERENCES}

Amory, J. R., Z. E. Barker, J. L. Wright, S. A. Mason, R. W. Blowey, and L. E. Green. 2008. Associations between sole ulcer, white line disease and digital dermatitis and the milk yield of 1824 dairy cows on 30 dairy cow farms in England and Wales from February 2003-November 2004. Prev. Vet. Med. 83:381-391.

Anil, L., S. S. Anil, and J. Deen. 2005. Pain detection and amelioration in animals on the farm: issues and options. J. Appl. Anim. Welf. Sci. 8:261-278.

Barker, Z. E., K. A. Leach, H. R. Whay, N. J. Bell, and D. C. Main. 2010. Assessment of lameness prevalence and associated risk factors in dairy herds in England and Wales. J. Dairy Sci. 93:932-941.
Becker, J., M. Reist, and A. Steiner. 2014a. Factors influencing the attitudes of cattle veterinarians, farmers, and claw trimmers towards the pain associated with the treatment of sole ulcers and the sensitivity to pain of dairy cows. Vet. J. 200:38-43.

Becker, J., A. Steiner, S. Kohler, A. Koller-Bahler, M. Wuthrich, and M. Reist. 2014b. Lameness and foot lesions in Swiss dairy cows: I. Prevalence. Schweiz. Arch. Tierheilkd. 156:71-78.

Bennett, R. M., K. Christiansen, and R. S. Clifton-Hadley. 1999. Estimating the costs associated with endemic diseases of dairy cattle. J. Dairy Res. 66:455-459.

Bicalho, R. C., V. S. Machado, and L. S. Caixeta. 2009. Lameness in dairy cattle: A debilitating disease or a disease of debilitated cattle? A cross-sectional study of lameness prevalence and thickness of the digital cushion. J. Dairy Sci. 92:3175-3184.

Braun, U., T. Tschoner, and M. Hassig. 2014. Evaluation of eating and rumination behaviour using a noseband pressure sensor in cows during the peripartum period. BMC Vet. Res. 10:195.

Bruijnis, M. R., H. Hogeveen, and E. N. Stassen. 2010. Assessing economic consequences of foot disorders in dairy cattle using a dynamic stochastic simulation model. J. Dairy Sci. 93:2419-2432.

Buck, M., K. Friedli, B. Steiner, L. Gygax, B. Wechsler, and A. Steiner. 2013. Influence of manure scrapers on dairy cows in cubicle housing systems. Livest. Sci. 158:129-137.

Chapinal, N., A. M. de Passille, and J. Rushen. 2009a. Weight distribution and gait in dairy cattle are affected by milking and late pregnancy. J. Dairy Sci. 92:581-588.

Chapinal, N., A. M. de Passille, J. Rushen, and S. Wagner. 2010. Automated methods for detecting lameness and measuring analgesia in dairy cattle. J. Dairy Sci. 93:2007-2013.

Chapinal, N., A. M. de Passille, D. M. Weary, M. A. von Keyserlingk, and J. Rushen. 2009b. Using gait score, walking speed, and lying behavior to detect hoof lesions in dairy cows. J. Dairy Sci. 92:4365-4374.

Cramer, G., K. D. Lissemore, C. L. Guard, K. E. Leslie, and D. F. Kelton. 2008. Herd- and cow-level prevalence of foot lesions in Ontario dairy cattle. J. Dairy Sci. 91:3888-3895.

Dippel, S., M. Dolezal, C. Brenninkmeyer, J. Brinkmann, S. March, U. Knierim, and C. Winckler. 2009a. Risk factors for lameness in cubicle housed Austrian Simmental dairy cows. Prev. Vet. Med. 90:102-112.

Dippel, S., M. Dolezal, C. Brenninkmeyer, J. Brinkmann, S. March, U. Knierim, and C. Winckler. 2009b. Risk factors for lameness in freestall-housed dairy cows across two breeds, farming systems, and countries. J. Dairy Sci. 92:5476-5486.

Dirksen, G. 1990. Bewegungsapparat. Pages 549-591 in Die klinische Untersuchung des Rinders. Vol. 1. 3rd ed. G. Dirksen, H. D. Gründer, and M. Stöber, ed. Paul Parey, Berlin and Hamburg, Germany.

Doll, K., D. Schillinger, and W. Klee. 1985. Der Glutaraldehyd-Test beim Rind-seine Brauchbarkeit für Diagnose und Prognose innerer Entzündungen. Zentralblatt für Veterinärmedizin Reihe A $32: 581-593$

Edmondson, A. J., I. J. Lean, L. D. Weaver, T. Farver, and G. Webster. 1989. A Body Condition Scoring Chart for Holstein Dairy Cows. J. Dairy Sci. 72:68-78.

Egger-Danner, C., P. Nielsen, A. Fiedler, K. Müller, T. Fjeldaas, D. Döpfer, V. Daniel, C. Bergsten, G. Cramer, A.-M. Christen, K. F. Stock, M. Holzhauer, A. Steiner, J. Clarke, N. Capion, N. Charfeddine, E. Pryce, E. Oakes, J. Burgstaller, B. Heringstad, C. Ødegård, and J. Kofler. 2015. ICAR Claw Health Atlas. Pages 6-7 in ICAR Technical Series. 1st ed. ICAR, Rome, Italy.

Espejo, L. A., M. I. Endres, and J. A. Salfer. 2006. Prevalence of lameness in high-producing holstein cows housed in freestall barns in Minnesota. J. Dairy Sci. 89:3052-3058.

Flower, F. C., and D. M. Weary. 2006. Effect of hoof pathologies on subjective assessments of dairy cow gait. J. Dairy Sci. 89:139-146.

Garbarino, E. J., J. A. Hernandez, J. K. Shearer, C. A. Risco, and W. W. Thatcher. 2004. Effect of lameness on ovarian activity in postpartum holstein cows. J. Dairy Sci. 87:4123-4131.

González, L. A., B. J. Tolkamp, M. P. Coffey, A. Ferret, and I. Kyriazakis. 2008. Changes in feeding behavior as possible indicators 
for the automatic monitoring of health disorders in dairy cows. J. Dairy Sci. 91:1017-1028.

Green, L. E., V. J. Hedges, Y. H. Schukken, R. W. Blowey, and A. J. Packington. 2002. The impact of clinical lameness on the milk yield of dairy cows. J. Dairy Sci. 85:2250-2256.

Hanley, J. A., and B. J. McNeil. 1982. The meaning and use of the area under a receiver operating characteristic (ROC) curve. Radiology 143:29-36.

Holzhauer, M., C. Hardenberg, and C. J. Bartels. 2008. Herd and cowlevel prevalence of sole ulcers in The Netherlands and associatedrisk factors. Prev. Vet. Med. 85:125-135.

Hudson, C., H. Whay, and J. Huxley. 2008. Recognition and management of pain in cattle. In Pract. 30:126-134.

Just, L. 2014. Validation of a pedometer system for recording lying behavior in dairy cattle. MS Thesis. University of Bern, Switzerland, Bern, Switzerland.

Kossaibati, M. A., and R. J. Esslemont. 1997. The costs of production diseases in dairy herds in England. Vet. J. 154:41-51.

Lasko, T. A., J. G. Bhagwat, K. H. Zou, and L. Ohno-Machado. 2005. The use of receiver operating characteristic curves in biomedical informatics. J. Biomed. Inform. 38:404-415.

Leach, K. A., H. R. Whay, C. M. Maggs, Z. E. Barker, E. S. Paul, A. K. Bell, and D. C. Main. 2010a. Working towards a reduction in cattle lameness: 1 . Understanding barriers to lameness control on dairy farms. Res. Vet. Sci. 89:311-317.

Leach, K. A., H. R. Whay, C. M. Maggs, Z. E. Barker, E. S. Paul, A. K. Bell, and D. C. Main. 2010b. Working towards a reduction in cattle lameness: 2. Understanding dairy farmers' motivations. Res. Vet. Sci. 89:318-323.

Manske, T., J. Hultgren, and C. Bergsten. 2002. Prevalence and interrelationships of hoof lesions and lameness in Swedish dairy cows. Prev. Vet. Med. 54:247-263.

Mohr, E., J. Langbein, and G. Nurnberg. 2002. Heart rate variability: A noninvasive approach to measure stress in calves and cows. Physiol. Behav. 75:251-259.

Neveux, S., D. M. Weary, J. Rushen, M. A. von Keyserlingk, and A. M. de Passille. 2006. Hoof discomfort changes how dairy cattle distribute their body weight. J. Dairy Sci. 89:2503-2509.

Nordmann, E., N. M. Keil, C. Schmied-Wagner, C. Graml, J. Langbein, and J. Aschwanden. 2011. Feed barrier design affects behaviour and physiology in goats. Appl. Anim. Behav. Sci. 133:40-53.

Offinger, J., S. Herdtweck, A. Rizk, A. Starke, M. Heppelmann, H. Meyer, S. Janssen, M. Beyerbach, and J. Rehage. 2013. Postoperative analgesic efficacy of meloxicam in lame dairy cows undergoing resection of the distal interphalangeal joint. J. Dairy Sci. 96:866-876.

Pastell, M., L. Hanninen, A. M. de Passille, and J. Rushen. 2010. Measures of weight distribution of dairy cows to detect lameness and the presence of hoof lesions. J. Dairy Sci. 93:954-960.

Pastell, M. E., and M. Kujala. 2007. A probabilistic neural network model for lameness detection. J. Dairy Sci. 90:2283-2292.
Rushen, J., E. Pombourcq, and A. M. de Passillé. 2007. Validation of two measures of lameness in dairy cows. Appl. Anim. Behav. Sci. 106:173-177.

Russell, A. M., G. J. Rowlands, S. R. Shaw, and A. D. Weaver. 1982 Survey of lameness in British dairy cattle. Vet. Rec. 111:155-160.

Sepúlveda-Varas, P., D. M. Weary, and M. A. von Keyserlingk. 2014 Lying behavior and postpartum health status in grazing dairy cows. J. Dairy Sci. 97:6334-6343.

Somers, J. G., K. Frankena, E. N. Noordhuizen-Stassen, and J. H. Metz. 2003. Prevalence of claw disorders in Dutch dairy cows exposed to several floor systems. J. Dairy Sci. 86:2082-2093.

Sprecher, D. J., D. E. Hostetler, and J. B. Kaneene. 1997. A lameness scoring system that uses posture and gait to predict dairy cattle reproductive performance. Theriogenology 47:1179-1187.

Starke, A., M. Heppelmann, M. Beyerbach, and J. Rehage. 2007. Septic arthritis of the distal interphalangeal joint in cattle: Comparison of digital amputation and joint resection by solar approach Vet. Surg. 36:350-359.

Tarvainen, M. P., J. P. Niskanen, J. A. Lipponen, P. O. Ranta-Aho, and P. A. Karjalainen. 2014. Kubios HRV - Heart rate variability analysis software. Comput. Methods Programs Biomed. 113:210220 .

Tarvainen, M. P., P. O. Ranta-Aho, and P. A. Karjalainen. 2002. An advanced detrending method with application to HRV analysis. IEEE Trans. Biomed. Eng. 49:172-175.

Tranter, W. P., and R. S. Morris. 1991. A case study of lameness in three dairy herds. N. Z. Vet. J. 39:88-96.

Vasseur, E., J. Rushen, D. B. Haley, and A. M. de Passille. 2012. Sampling cows to assess lying time for on-farm animal welfare assessment. J. Dairy Sci. 95:4968-4977.

von Borell, E., J. Langbein, G. Despres, S. Hansen, C. Leterrier, J. Marchant-Forde, R. Marchant-Forde, M. Minero, E. Mohr, A. Prunier, D. Valance, and I. Veissier. 2007. Heart rate variability as a measure of autonomic regulation of cardiac activity for assessing stress and welfare in farm animals-a review. Physiol. Behav 92:293-316.

Warnick, L. D., D. Janssen, C. L. Guard, and Y. T. Grohn. 2001. The effect of lameness on milk production in dairy cows. J. Dairy Sci. 84:1988-1997.

Yunta, C., I. Guasch, and A. Bach. 2012. Short communication: Lying behavior of lactating dairy cows is influenced by lameness especially around feeding time. J. Dairy Sci. 95:6546-6549.

Zahid, U. N., S. S. Randhawa, S. A. Hussain, S. S. Randhawa, V. Mahajan, and K. Dua. 2014. Claw lesions causing clinical lameness in lactating holstein frisian crossbred cows. Vet. Med. Int. 2014:764689.

Zehner, N. 2012. Validation of a new method (RumiWatch) for combined automatic measurement of rumination, feed intake and locomotion in dairy cows. MS Thesis. Institut für Landwirtschaftliche Verfahrenstechnik Agrar- und Ernährungswissenschaftliche Fakultät, Christian-Albrechts-Universität Kiel, Kiel, Germany. 